\title{
Efficacy of nifedipine in the treatment of angina pectoris and chronic airways obstruction
}

\author{
S. S. JAIPRAKASH \\ M.B. B.S., M.R.C.P. \\ S. S. Chatterjee \\ M.B. B.S., F.R.C.P.
}

J. N. SAhaY

M.D.

G. MACDONALD

M.B., Ch.B., M.R.C.G.P.

Departments of Respiratory Physiology, and of Cardiology, Wythenshawe Hospital, Manchester

\begin{abstract}
Summary
Twenty patients suffering from angina pectoris with co-existing fixed or labile airways obstruction, were administered fortnightly treatment periods of nifedipine or matching placebo over an 8-week period. Maintenance treatment for their airways obstruction continued throughout this period. Nifedipine was found to be an effective drug in controlling their angina, and did not have an adverse effect on the airways obstruction. Both systolic and diastolic BP was reduced over a 90-min period after administration of a single dose of nifedipine.
\end{abstract}

\section{Introduction}

Nifedipine (Adalat) a calcium antagonist, has been shown to be a useful drug in the treatment of stable angina pectoris (Kenmure and Scruton, 1979). It is particularly effective in reducing the frequency, intensity and duration of anginal attacks (Alvarado and Pineros, 1976). There is also an increase in total work capacity and decrease in therapeutic glyceryl trinitrate consumption (Ekelund and Oro, 1976; Moskowitz et al., 1979). The resting ECG improves (Alvarado and Pineros, 1976). It has also been shown to be more effective than placebo in diminishing ST segment depression during exercise ECG (Becker, Kaltenbach and Kober, 1975). It evokes a small but definite decrease in systolic and diastolic BP at rest (Ekelund and Oro, 1976; Kenmure and Scruton, 1979). There have not been any serious side effects noted, but few controlled studies have been undertaken in patients suffering from both angina and airways obstruction. The authors have assessed the efficacy of nifedipine in patients with co-existing angina pectoris and fixed or labile airways obstruction.

\section{Materials and methods}

Twenty patients with proved chronic airways obstruction and at least a 3-month history of typical, stable recurrent effort angina occurring $\geqslant 4$ times/week and relieved by rest, with or without glyceryl trinitrate, were selected for the trial. New patients or those already on anti-anginal therapyO including $\beta$-blockers, were included, but all anti anginal therapy except therapeutic glyceryl trinitrate was gradually withdrawn over 10 to 14 days, and stopped before entry into the trial. The following patients were excluded: those $>70$ years of age; women of childbearing age; those with status asthmaticus, congestive cardiac failure, valvular heart disease, malignant hypertension, or myocardial infarction within the previous 3 months.

The patients were advised of the nature and object of the trial, and their informed consent in writing was obtained. Lung function was assessed, and those with fixed or labile airways obstruction were identified. The patients were treated for 8 weeks in the following manner:

$\begin{array}{lll}\text { Stage } & \text { Weeks } & \text { Treatment (all } 3 \text { times/day) } \\ \text { I } & 1-2 & \text { Placebo to match nifedipine } \\ \text { II } & 3-4 & \text { Nifedipine } 10 \mathrm{mg} \\ \text { III } & 5-6 & \text { Placebo to match nifedipine } \\ \text { IV } & 7-8 & \text { Nifedipine } 10 \mathrm{mg}\end{array}$

Throughout this period the patients were allowed to continue with their pre-entry treatment for airways obstruction, i.e. oral or aerosol bronchodilators, or steroids. At entry and on the 14th day of each stage of treatment, exercise testing was undertaken, commencing at $2.7 \mathrm{~km} / \mathrm{hr}$ at $5.7^{\circ}$ slope for $3 \mathrm{~min}$. The speed was increased by $2 \mathrm{~km} / \mathrm{hr}$ every 3 min until the onset of symptoms, either anginal 
pain, shortness of breath, exhaustion, pain in the calf muscles or ECG changes. The ECG and heart rate were monitored throughout the exercise, but the BP was measured before and after exercise. After full recovery from the exercise test, the patient proceeded to whole body plethysmography, where forced expiratory volume $\left(\mathrm{FEV}_{\mathbf{1}}\right)$, vital capacity (VC), airways resistance (Raw) and peak expiratory flow rate (PEFR) were measured, with further determinations of BP and heart rate. At entry, the patient was given, according to the randomization, a single capsule of either nifedipine or matching placebo, and his or her lung function tests, BP and heart rate were recorded $15,30,45,60$ and 90 min after ingestion of the capsule. The singe capsule of opposite nature, i.e. placebo or active drug was similarly administered at week 2 whilst the patient was on maintenance placebo therapy, and lung function tests, BP and heart rate assessed at the same intervals.

At weeks 4, 6 and 8, lung function tests, BP and heart rate were repeated before and $5 \mathrm{~min}$ after an inhalation of $200 \mu \mathrm{g}$ salbutamol. At each visit, the drug supplies from the previous stage were collected and counted, and a new supply of nifedipine or matching placebo, with pre-counted therapeutic glyceryl trinitrate, an angina record card and a further appointment were issued.

Patients were asked:

whether they had taken their drugs correctly; the weekly frequency of angina and the weekly consumption of glyceryl trinitrate. Their statements were checked against the angina diary cards and returned drug supplies;

whether the treatment had affected their angina, their breathing, or both; the severity was graded; whether the treatment upset them in any way; the nature of side effects was recorded.

The results were analysed by the paired ' $t$ ' test. On conclusion of the study, the patients were allowed to continue with nifedipine or return to their previous therapy according to their response.

\section{Results}

Of the 20 patients entering the study, 19 were male. Seventeen completed the protocol. Two were withdrawn because their anginal attacks were not relieved, and they reverted to their original antianginal therapy. A third 'dropped out' having left the district, but his data from the single dose response at entry and week 2 are included in this part of the analysis incorporating 18 patients.

Symptomatically the patients reported a decreased frequency of anginal attacks at the end of the first nifedipine period compared to the previous 2-week period of placebo $(P<0.03)$. This effect persisted during stages III and IV. A corresponding trend was noted regarding the consumption of therapeutic glyceryl trinitrate.

The mean duration of exercise increased during the first placebo period, and continued to increase during the next 3 stages. The time of onset of angina during the exercise ECG showed significant improvement $(P<0.005)$ at the end of the second nifedipine treatment stage as compared to that of the preceding placebo period (Fig. 1).

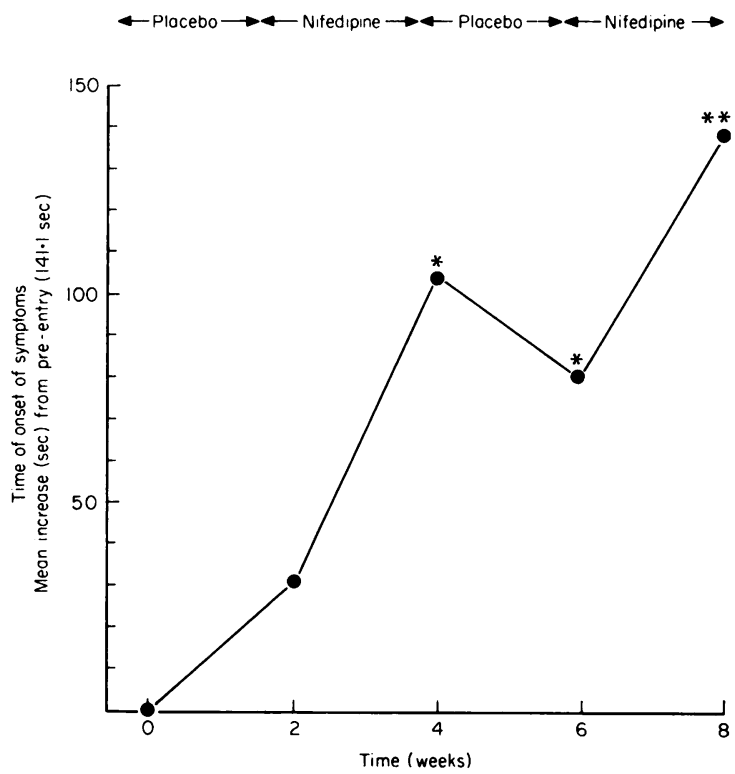

Fig. 1. Time-course of the increase in time to onset of angina/end-point symptoms during exercise, produced by nifedipine or placebo. Each point represents the mean value for 17 patients. Significantly increased from pre-entry ${ }^{*}=P<0.01,{ }^{* *}=P<0.001$. Week $8 v$. week 2 , $P<0.002$; week $8 v$. week $4, P<0.05$; week $8 v$. week 6 , $P<0.005$.

At the pre-entry exercise ECG for the 17 patients, the end-point in 7 was angina and shortness of breath, 6 had angina, 3 had shortness of breath and one had ECG changes. At the end of the second nifedipine period, the nature of the end-point in 6 was angina, in 4 shortness of breath, in 2 angina and shortness of breath. The remaining 5 patients had experienced different symptoms necessitating termination of the exercise test, namely ECG changes, exhaustion, pain in the legs, dyspnoea and tired legs, and angina and tiredness.

In the single dose study, the mean systolic and diastolic BPs at $90 \mathrm{~min}$ were both reduced significantly $(P<0.001)$ by nifedipine, the maximum systolic fall occurring at $30 \mathrm{~min}$ (Fig. 2). The mean 
drop in diastolic blood pressure on nifedipine $(-17 \mathrm{mmHg})$ compared to the mean drop on placebo $(-3 \mathrm{mmHg})$ at $90 \mathrm{~min}$ was also statistically significant $(P<0.005)$.

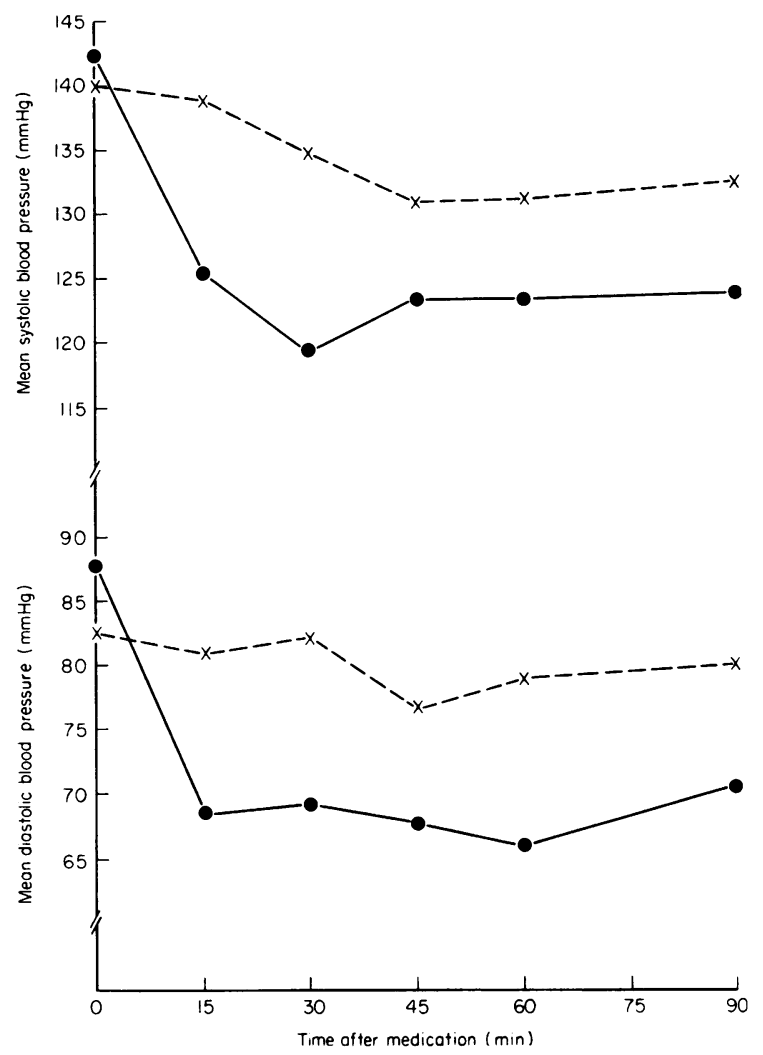

FIG. 2. Time-courses of the falls in systolic and diastolic BP produced by a single dose of nifedipine ( -0$)$ or placebo $(x---x)$. Each point is the mean value for 18 patients.

The mean standing heart rate was unaffected by nifedipine, from 15 to 90 min after taking the single capsule.

The lung function tests determined in 11 patients with fixed and 7 with labile airways obstruction, 15, 30,45 and 90 min after administration of a single capsule of either placebo or active nifedipine at entry or week 2 , showed no significant change in FEV $_{1}$, VC and Raw. The PEFR at 90 min increased with the active drug as compared with the placebo $(P<0.005)$. The increase was more marked between 15 and 45 min with a peak rise at 30 min (Fig. 3).

The increase of $\mathrm{FEV}_{1}$ determined after 14 days active nifedipine, and $5 \mathrm{~min}$ after salbutamol inhalation was statistically significant $(P<0.05)$ in the patients having labile airways obstruction as

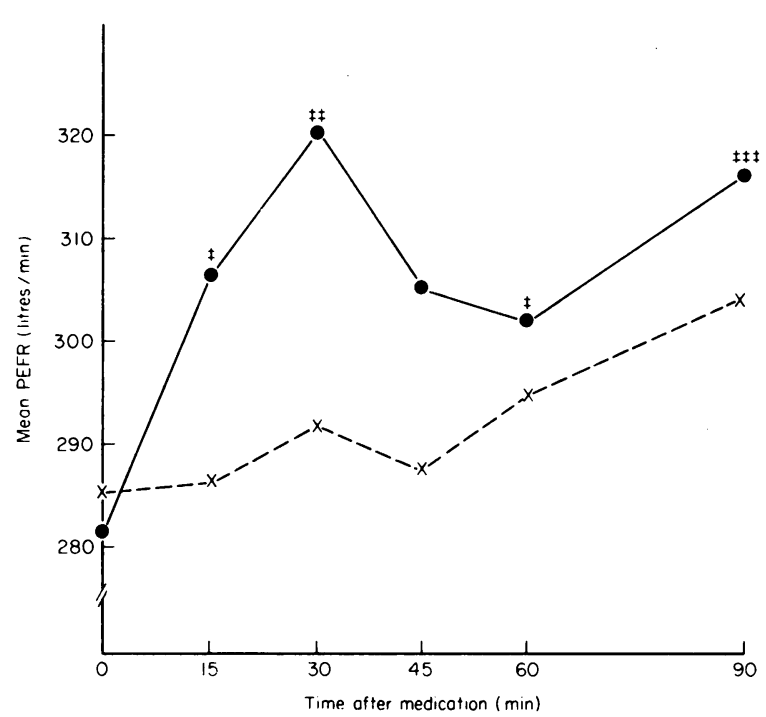

FIG. 3. Time-courses of peak expiratory flow rate after a single dose of nifedipine (O-O) or placebo). $(x---x)$. Each point is the mean value for 18 patients. Significantly different from baseline $\ddagger=$ $P<0.05, \ddagger \ddagger=P<0.0, \ddagger \ddagger=P<0.01$.

compared to those with fixed airways obstructiong when compared with placebo. The PEFR showed as statistically significant improvement in both active $(P<0.002)$ and placebo $(P<0.02)$ phases in the $e^{+}$ labile group of airways obstruction patients.

Seven patients on placebo therapy volunteered a total of 15 side effects, which did not affect continued participation in the study. These included dizziness (5), headaches (3), nausea (2), numbness of fingers, deafness, diarrhoea, exhaustion and palpitation (one of each). Six of the same 7 patients reported a total of 9 mild side effects on active therapy, frequently of identical nature to those mentioned in the preceding placebo phase, i.e. dizziness (2) headaches (2), nausea (2), numbness of fingers, deafness, palpitations and flushing (one of each). Ten patients did not have any side effects and no patient had unwanted symptoms on active therapy alone.

\section{Discussion}

Angina pectoris is a disabling symptom of ischaemic heart disease for many patients. Shortacting nitrates and $\beta$-adrenergic receptor blocking drugs have been the mainstay of anti-anginal therapy in recent years, but such therapy is ineffective in some patients, and produces unpleasant adverse reactions in others.

Some patients with airways obstruction due to asthma or chronic bronchitis have developed 
bronchoconstriction when treated with $\beta$-adrenergic blocking agents (McNeill, 1964; Sinclair, 1979). Theoretically, the problem might be avoided by the use of the newer cardioselective $\beta$-adrenergic antagonists, which lack activity on the $\beta_{2}$-receptors in bronchial smooth muscle, but their effect in these patients is unpredictable; careful surveillance is required when treating angina or hypertension with $\beta$-adrenergic blocking drugs in patients with coexisting obstructive airways disease (Skinner et al., 1976), and such patients may be helped by the concomitant use of $\beta_{2}$-stimulants (Tivenius, 1976). Unfortunately, latent asthma may be exacerbated by both cardioselective and non-selective $\beta$ adrenergic blocking agents, with long-lasting respiratory distress necessitating steroids many months after discontinuation of the causative therapy (Anderson et al., 1979).

Alternative therapy devoid of an effect on $\beta$ receptors might benefit this group of patients, and this controlled study demonstrates that nifedipine relieves the symptoms of stable angina pectoris without producing an adverse effect on co-existing fixed or labile airways obstruction. Four patients whose stress test were terminated by angina whilst on placebo, showed improved exercise tolerance after 2 weeks of nifedipine treatment, the end-point being unrelated to chest pain. Overall improvement of exercise tolerance in the nifedipine group suggests that the compound is more effective in the control of angina than placebo, although the degree of response varied considerably from patient to patient. Fourteen days' treatment with nifedipine may be less than the optimal period for evaluation (Cocco et al., 1979), and in the present group of patients, no anti-anginal benefit was observed in some patients, whilst others demonstrated significant subjective and objective improvement, confirming earlier work (Hollmann et al., 1975).

Nifedipine has been reported as relieving spasm in visceral smooth muscle in vivo in the uterus (Ulmsten, Andersson and Forman, 1978; Andersson et al., 1979), oesophagus (Weiser et al., 1977; Blackwell, Holt and Heading, 1979), and urinary tract (Forman et al., 1978). The authors cannot explain the increase in PEFR alone following a single dose of nifedipine, without there being an effect on FEV, or FVC, and further work is required to elucidate this point.

Nifedipine has been shown to have a potent effect in lowering BP in hypertensive patients (Lederballe Pedersen and Mikkelsen, 1978, Bartorelli et al., 1979). Normotensives monitored for $120 \mathrm{~min}$ following administration of a single dose $(10 \mathrm{mg})$, were reported to show no effect on BP, although the heart rate increased (Corea et al., 1979). In contrast, in the present series of 18 patients of whom only 2 had a mildly elevated BP $>160 / 95 \mathrm{mmHg}$, with 2 additional patients having base-line determinations of $180 / 60$ and $150 / 110 \mathrm{mmHg}$, there was a marked lowering of systolic and diastolic pressure over $90 \mathrm{~min}$, without reflex tachycardia.

In conclusion, 14 days' nifedipine therapy did not produce any adverse effect on any parameter of respiratory function, and it appears that nifedipine is an effective anti-anginal agent which may be prescribed with safety to patients with co-existing fixed or labile obstructive airways disease.

\section{Acknowledgements}

The authors wish to thank Mr J. Bailey and Dr T. W. K. Hill for their advice and help, and Dr C. L. Bray and Dr R. S. Croxson for referral of some of their patients.

\section{References}

Alvarado, E. \& Pineros, J. (1976) The efficacy of Adalat in angina pectoris patients. Results of a six-month trial. In: Third International Adalat Symposium. (Ed by Jatene, A.D. \& Lichtlen, P.R.), p. 261, Excerpta Medica, Amsterdam.

Anderson, E.G., Calcraft, B., Jariwalla, A.G. \& Al-ZaibaK, M. (1979) Persistent asthma after treatment with beta-blocking drugs. British Journal of Diseases of the Chest, 73, 407.

ANDERSSON, K.-E., Ingemarsson, I., Ulmsten, U. \& WINGERUP, L. (1979) Inhibition of prostaglandin-induced uterine activity by nifedipine. British Journal of Obstetrics and Gynaecology, 86, 175.

Bartorelli, C., Magrini, F., Moruzzi, P., Olivari, M.T., Polese, A., Fiorentini, C. \& GuazzI, M. (1978) Haemodynamic effects of a calcium antagonistic agent (nifedipine) in hypertension: therapeutic implications. Clinical Science and Molecular Medicine, 55, $291 \mathrm{s.}$

Becker, H.-J., Kaltenbach, M. \& Kober, G. (1975) Comparison of the effects of Adalat with other substances on myocardial ischaemia under loading conditions. In: Second International Adalat Symposium. (Ed by Lochner, W., Braasch, W. \& Kroneberg, G.), p. 156, Springer Verlag, Berlin.

Blackwell, J.N., Holt, S. \& Heading, R.C. (1979) Effect of nifedipine on oesophageal motility. (Abstract) Autumn Meeting of the British Society of Gastroenterology, 46.

Cocco, G., Strozzi, C., ChU, D., Amrein, R. \& Castagnoli, E. (1979) Therapeutic effects of pindolol and nifedipine in patients with stable angina pectoris and asymptomatic resting ischaemia. European Journal of Cardiology, 10, 59.

Corea, L., Miele, N., Bentivoglio, M., Boschetti, E., Agabiti-Rosei, E. \& Muiesan, G. (1979) Acute and chronic effects of nifedipine on plasma renin activity and plasma adrenaline and noradrenaline in controls and hypertensive patients. Clinical Science, 57, $115 \mathrm{~s}$.

EKELUND, L.-G. \& ORo, L. (1979) Anti-anginal efficiency of nifedipine with and without a beta-blocker, studied with exercise test. A double-blind, randomized subacute study. Clinical Cardiology, 2, 203.

Forman, A., Andersson, K.-E., Henriksson, L., Rud, T. \& UlMSTEN, U. (1978) Effects of nifedipine on the smooth muscle of the human urinary tract in vitro and in vivo. Acta pharmacologica et toxicologica, 43, 111.

Hollmann, W., Rost, R., Liesen, H. \& Emirkanian, $O$. (1975) The cardiopulmonary loading capacity in healthy 
persons and patients with coronary heart disease after application of Adalat. In: Second International Adalat Symposium. (Ed by Lochner, W., Braasch, W. \& Kroneberg, G.), p. 243. Springer-Verlag, Berlin.

Kenmure, A.C.F. \& Scuron, J.H. (1979) A double-blind controlled trial of the anti-anginal efficacy of nifedipine compared with propranolol. British Journal of Clinical Practice, 33, 49.

Lederballe Pedersen, O. \& Mikkelsen, E. (1978 Acute and chronic effects of nifedipine in arterial hypertension. European Journal of Clinical Pharmacology, 14, 375.

MCNeILL, R.S. (1964) Effect of a $\beta$-adrenergic blocking agent, propranolol on asthmatics. Lancet, ii, 1101.

Moskowitz, R.M., Piccini, P.A., NaCarelli, G.V. \& ZeLIS, R. (1979) Nifedipine therapy for stable angina pectoris: preliminary results of effects on angina frequency and treadmill exercise response. American Journal of Cardiology, 44, 811.

SinCLAIR, D.J.M. (1979) Comparison of effects of propran- olol and metoprolol on airways obstruction in chronic bronchitis. British Medical Journal, 1, 168.

Skinner, C., Gaddie, J., Palmer, K.N.V. \& Kerridge, D.F. (1976) Comparison of effect of metoprolol and propranolol on asthmatic airway obstruction. British Medical Journal, 1, 504.

Tivenius, L. (1976) Effects of multiple doses of metoprolol and propranolol on ventilatory function in patients with chronic obstructive lung disease. Scandinavian Journal of Respiratory Disease, 57, 190.

Ulmsten, U., ANDERsSON, K.-E. \& Forman, A. (1978) Relaxing effects of nifedipine on the non-pregnant human uterus in vitro and in vivo. Obstetrics and Gynecology, 52, No. 4, 436.

Weiser, H.F., Lepsein, G., Golenhofen, K., SchattenmanN, G. \& SiewerT, R. (1977) Clinical and experimental studies relating to the action of nifedipine on the smooth musculature of the oesophagus. Zeitschrift für Gastroenterologie, 15, 11, 691 . 